\title{
A population-based audit of ethnicity and breast cancer risk in one general practice catchment area in North London, UK: implications for practice
}

\author{
Michelle Ferris', Douglas F. Easton², Rebecca J. Doherty', Brian H.J. Briggs', Michelle Newman', Ifthikhar M. Saraf', \\ Sarah Scambler', Lyndon Wagman', Michael T. Wyndham', Ann Ward', Rosalind A. Eeles ${ }^{5}$ \\ 'Lane End Medical Group, Lane End House, 25 Edgwarebury Lane, Edgware, Middx, HA8 8L, United Kingdom \\ 2Cancer Research UK Genetic Epidemiology Group, Strangeways Laboratory, Worts Causeway, Cambridge, CB1 8RN, United Kingdom \\ ${ }^{3}$ Royal Marsden NHS Foundation Trust, Downs Road, Sutton, Surrey, SM2 5PT, United Kingdom \\ ${ }^{4}$ Royal Marsden NHS Foundation Trust, Fulham Road, London, SW3 6JJ, United Kingdom \\ 5 Institute of Cancer Research and Royal Marsden NHS Trust, London and Sutton, Surrey, SM2 5NG, United Kingdom
}

Key words: breast cancer risk, Ashkenazi

Corresponding author: Rosalind Eeles, Institute of Cancer Research and Royal Marsden NHS Foundation Trust, Cancer Genetics Unit, Orchard House, Downs Road, Sutton, SM2 5NG, United Kingdom, phone +44 2086613642 , fax: +44 2087701489 E-mail: Rosalind.Eeles@icr.ac.uk

Submitted: 25 July 2007

Accepted: 7 September 2007

\begin{abstract}
Objectives: To conduct a pilot population-based study within a general practice catchment area to determine whether the incidence of breast cancer was increased in the Ashkenazi population.

Design: Population-based cohort study.

Setting: A single general practice catchment area in North London.

Participants: 1947 women over the age of 16 who responded to a questionnaire about ethnicity and breast cancer. Main outcome measures: Incidence of breast cancer, ethnicity.

Results: This study showed a 1.5 -fold $(95 \% \mathrm{Cl} 0.93-2.39)$ increase in breast cancer risk in the Ashkenazim compared with the non-Ashkenazi white population. The increased incidence was for both premenopausal and postmenopausal breast cancer (expected incidence pre:post is $1: 4$ whereas in the Ashkenazim it was $1: 1 ; 51$ and $52 \%$ of cases respectively). This increase was not shown in the Sephardim. Asians had a reduction in incidence $(\mathrm{OR}=0.44 ; 95 \% \mathrm{Cl} 0.10-1.89)$. Results were adjusted for other risk factors for breast cancer.

Conclusions: This study showed a 1.5-fold increase in breast cancer rates in Ashkenazim compared with the nonJewish white population when adjusted for age (i.e. corrections were made to allow comparison of age groups) and this is not observed in the Sephardic population. The proportion of premenopausal breast cancer was just over double that of the general population. This is the first general practice population-based study in the UK to address this issue and has implications for general practitioners who care for patients from the Ashkenazi community.
\end{abstract}

\section{Introduction}

General practice offers the doctor the privilege of caring for individuals and their families over many episodes and sometimes for many years, allowing doctors a unique insight into the impact of health and illness on individuals' physical and psychosocial wellbeing. This study was undertaken in a GP practice in a multi-ethnic catchment area in North-West London with a high proportion of Jewish families. Within this practice there 
was an apparent cluster of breast cancer diagnoses in young Jewish women under 45 years, a diagnosis which had obvious medical and psychosocial consequences for both the women themselves and their young families. This also had a presumed extended impact upon the closeknit Jewish community and an observed impact on the general practice staff and palliative care teams.

An increased frequency of germline mutations in the breast cancer predisposition genes BRCA1 and BRCA2 is known to exist within the Ashkenazi Jewish population [1-3]. Several authors have investigated whether there is an increased breast cancer incidence in this population, with varying results. Newill [4] noted an increased incidence of breast cancer within the New York Jewish population in the late 1950s. Egan et al. [5] found that, while the relative risk of breast cancer was not significantly different for Ashkenazi women in general, there was a slight elevation in relative risk for younger women. There was a greater increase in relative risk for women with a family history of cancer than there was for similar women of different religious background. This was again based on a population of American women. Feldman [6] did not find any evidence of increased breast cancer risk for Ashkenazi women. Breast cancer incidence is lower in Israel, which has a larger proportion of Ashkenazi Jewish individuals, than in Northern European countries such as the United Kingdom [7].

The local observation in general practice of a large number of young breast cancer cases prompted MF, in collaboration with the co-authors and Prof Modell (see acknowledgements), to determine if this apparent increased incidence of breast cancer in the Jewish community was a real effect and also whether it was uniform across different types of Jewish origin.

\section{Materials and methods}

The audit was set in one general practice in North West London. The general practice serves a population of 11000 of whom 4772 were females over the age of 16 years. A computer search (Vision, In Practice) was conducted to ascertain all the cases of breast cancer within the general practice. The search used the interrogations "breast cancer" or "tamoxifen treatment". Sixty-six women thus identified were sent a questionnaire to determine their age at diagnosis, menopausal status at diagnosis, lifetime oral contraceptive (OC) and hormone replacement therapy (HRT) use, smoking and breast feeding history, and family history of breast, ovarian or colorectal cancer. They were asked in detail about their ethnicity; in particular, those who were Jewish were further characterised as being from one of the two diaspora, either the Sephardim (of Mediterranean origins) or Ashkenazim (from Eastern Europe), because until recently these two populations lived in relative isolation from each other over a number of centuries.

The remaining women in the general practice were sent an amended questionnaire to identify a further cohort of breast cancer cases whose breast cancer diagnoses predated the computerisation of the GP or before tamoxifen was used for breast cancer treatment. This cohort comprised women diagnosed with breast cancer before 1990. The amended questionnaire also provided details of breast cancer risk factors in the unaffected female population.

The recruitment letter and questionnaire were designed to capture information on known or suspected risk factors for breast cancer in the whole general practice population. An ethnicity section was included, but neither the recruitment letter nor the questionnaire emphasised this to avoid bias due to non-response in one group.

Odds ratios for breast cancer were estimated using logistic regression, adjusting for age in ten-year strata.

\section{Results}

This study was conducted in 1999. The general practice population catchment size was 11000 of whom 4772 were females over the age of 16 years. Twelve were deemed too ill or too anxious to be sent a questionnaire. All of these 4760 women were sent a questionnaire and 1947 women responded $141 \%$ response rate). 1637 of the 1947 were in the groups listed in Table 1. The other ethnic groups were too various for a robust analysis (the classification of other was Afro-Caribbean, Mediterranean and other). There were 93 breast cancer cases aged 29-90 years; median 41.5 years. Sixty-six were identified from the computerised records and a further 27 from the questionnaires sent to all women over 16 years. All 93 answered the questionnaire. 39.4\% of the general practice's women were Ashkenazi Jewish; however 51\% of the premenopausal cancers were in the Ashkenazim and $52 \%$ of the postmenopausal cases also.

Table 1 shows that the point-estimated breast cancer risk is 1.5-fold higher among Ashkenazi women than non-Jewish whites, though the difference is not significant $(O R=1.49,95 \% \mathrm{Cl} 0.93-2.39 ; p=0.10)$. The increased breast cancer risk is seen in both premenopausal and postmenopausal women (>50 years and $<50$ years respectively). The Sephardic population has rates nearer to those of the white population, though again the differences are not significant. However, the population of the Sephardim is small (7 questionnaires and 2 breast cancers). The rates for Asians are just under half those of whites and 
just under a third of those in the Ashkenazim. Table 2 shows the distribution of age, breastfeeding, menopausal status, $\mathrm{OC}$ use and HRT use by ethnic group (both those affected and unaffected with breast cancer). Table 3 shows that all other groups are more likely to breastfeed and to use hormone replacement therapy (HRT) than whites; however, the Sephardim and Asians have less oral contraceptive (OC) use than whites

Table 1. Breast cancer $(\mathrm{BrCa})$ odds ratios $(\mathrm{OR})$, relative to non-Jewish whites

\begin{tabular}{lccc}
\hline Group & BrCa/Total & $\begin{array}{c}\text { OR }(95 \% \mathrm{Cl}) \\
\text { (adjusted for age) }\end{array}$ & $\begin{array}{c}\text { OR (95\% Cl) } \\
\text { (adjusted for age, breastfeeding, } \\
\text { OC and HRT) }\end{array}$ \\
\hline White & $32 / 735$ & 1.0 & 1.0 \\
\hline Ashkenazi & $47 / 712$ & $1.49(0.93-2.39)$ & $1.47(0.91-2.39)$ \\
\hline Sephardic & $2 / 57$ & $0.82(0.19-3.54)$ & $0.83(0.19-3.64)$ \\
\hline Asian & $2 / 133$ & $0.44(0.10-1.89)$ & $0.35(0.08-1.52)$ \\
\hline
\end{tabular}

Table 2. Distribution of other risk factors by ethnic group in the whole population who returned questionnaires

\begin{tabular}{lccccc}
\hline & & $\begin{array}{c}\text { White } \\
\text { No. (\%) }\end{array}$ & $\begin{array}{c}\text { Ashkenazi } \\
\text { No. (\%) }\end{array}$ & $\begin{array}{c}\text { Sephardic } \\
\text { No. (\%) }\end{array}$ & $\begin{array}{c}\text { Asian } \\
\text { No. (\%) }\end{array}$ \\
\hline Age at questionnaire completion & $<30$ & $36(5)$ & $47(6)$ & $2(3)$ & $16(12)$ \\
\cline { 2 - 6 } & $30-39$ & $97(13)$ & $71(9)$ & $9(15)$ & $30(22)$ \\
\cline { 2 - 6 } & $40-49$ & $100(13)$ & $126(17)$ & $9(15)$ & $34(25)$ \\
\hline & $50-59$ & $118(15)$ & $188(25)$ & $9(15)$ & $28(21)$ \\
\hline & $60-69$ & $112(15)$ & $111(15)$ & $15(25)$ & $16(12)$ \\
\hline Breastfeeding & $70-79$ & $131(17)$ & $85(11)$ & $3(5)$ & $10(7)$ \\
\hline Menopausal status & $80+$ & $169(22)$ & $129(17)$ & $12(20)$ & $1(1)$ \\
\hline ever & $366(48)$ & $417(55)$ & $40(69)$ & $84(62)$ \\
\hline never & $400(52)$ & $338(45)$ & $18(31)$ & $51(38)$ \\
\hline pre & $474(62)$ & $416(55)$ & $35(71)$ & $46(34)$ \\
\hline & post & $293(38)$ & $342(45)$ & $24(29)$ & $89(66)$ \\
\hline & ever & $348(45)$ & $394(52)$ & $27(46)$ & $56(41)$ \\
\hline
\end{tabular}

Table 3. Risk factor distributions by ethnic group overall (not divided by diagnosis). Odds ratios for each risk factor by ethnic group, relative to non-Jewish whites

\begin{tabular}{lccc}
\hline Factor & Ashkenazi & Sephardi & Asian \\
\hline Breastfeeding & $1.42(1.14-1.76)$ & $2.83(1.53-5.23)$ & $3.13(2.01-4.87)$ \\
\hline Menopause & $0.92(0.61-1.40)$ & $1.23(0.38-3.97)$ & $1.42(0.67-2.99)$ \\
\hline OC use & $1.06(0.81-1.40)$ & $0.76(0.38-1.51)$ & $0.26(0.17-0.42)$ \\
\hline HRT use & $1.74(1.30-2.32)$ & $2.05(1.00-4.20)$ & $1.84(1.04-3.24)$ \\
\hline
\end{tabular}


or the Ashkenazim. Adjustments for breastfeeding, $\mathrm{OC}$ and HRT use do not affect the results. The Asian population is markedly younger than the other groups.

\section{Discussion}

It is known from genetic testing studies in breast cancer patients in New York [1] that the Ashkenazim with breast cancer have a higher incidence of mutations in breast-cancer-predisposition genes. This is the first population-based study within a GP setting in the UK to determine the breast cancer incidence in this population.

We have shown that the breast cancer rates in the Ashkenazim are approximately 1.5-fold higher than in non-Jewish whites when adjusted for age and that these rates are not observed in the Sephardi population. The Asian community in this general practice catchment area has a lower breast cancer incidence than the nonJewish or white Jewish populations. The adjustment in the analysis which we have performed to account for confounders such as HRT use, since this is known to increase breast cancer risk, means that other factors are likely to be responsible.

It is known that the Ashkenazim have a higher proportion of founder mutations in the breast cancer predisposition genes BRCA1 and BRCA2 [1-3]; however, previous studies have been hospitalpopulation-based or have specifically targeted certain groups such as cancer patients. As the first GP-population-based study in the UK, this analysis reduces the ascertainment bias as the women involved were not self-selected. All the patients with a breast cancer diagnosis completed the health questionnaire, whereas only a proportion of those unaffected responded.

The increased breast cancer risk in the Ashkenazim is seen in both premenopausal and postmenopausal women; thus the general practitioners' perception that there was a higher rate of breast cancer in young Ashkenazim was correct. The incidence in postmenopausal Ashkenazim was similarly high. The increase in premenopausal breast cancers has implications for the recommended mode of screening as mammography in this age group is less sensitive. Although the confidence intervals include 1.00, this study has provided pilot data which indicate that there may be an increased breast cancer incidence in the Ashkenazim that is not explained by a difference in hormonal factors or family history in first-degree relatives.

This study raises some important issues. The pointestimate increased risk observed by us is not high enough to justify earlier mammographic screening from the NICE guidelines [8], which suggest screening for women whose increase in breast cancer risk is at least 1.7-fold. However, if substantiated, the findings of this study will have implications for GPs who care for individuals from this ethnic background as there should be a heightened awareness of breast cancer risk in the Ashkenazi Jewish population.

\section{Acknowledgments}

This study was undertaken in the memory of Nicola Goldfarb and Denise Pannick, whose next of kin have given us permission to quote their names. It would not have been possible without the assistance of Barry Ferris, Robert Ferris, Emily Ferris, Stuart Fortune, Eleanor Segall, Chantall Segall and Barbara Fortune for database creation, data entry and management. We would like to acknowledge Prof Michael Modell for help with the study design.

Funding was obtained from NocTEN, Cancer Research UK and Dr Eeles' discretionary fund at the Institute of Cancer Research. The research was conducted independently of the external funders.

\section{References}

1. Struewing JP, Abeliovich D, Peretz T, Avishai N, Kaback MM, Collins FS, Brody LC. The carrier frequency of the BRCA1 185 delAG mutation is approximately 1 percent in Ashkenazi Jewish individuals. Nat Genet 1995; 11: 198-200.

2. Oddoux C, Struewing JP, Clayton CM, Neuhausen S, Brody LC, Kaback M, Haas B, Norton L, Borgen P, Jhanwar S, Goldgar D, Ostrer H, Offit K. The carrier frequency of the BRCA2 6174delT mutation among Ashkenazi Jewish individuals is approximately 1\%. Nat Genet 1996; 14: 188-190.

3. Roa BB, Boyd AA, Volcik K, Richards CS. Ashkenazi Jewish population frequencies for common mutations in BRCA1 and BRCA2. Nat Genet 1996; 14: 185-187.

4. Newill VA. Distribution of cancer mortality among ethnic subgroups of the white population of New York City, 1953-1958. J Natl Cancer Inst 1961; 26: 405-417.

5. Egan KM, Newcomb PA, Longnecker MP, Trentham-Dietz A, Baron JA, Trichopoulos D, Stampfer MJ, Willett WC. Jewish religion and risk of breast cancer. Lancet 1996; 347: 1645-1646.

6. Feldman GE. Do Ashkenazi Jews have a higher than expected cancer burden? Implications for cancer control prioritization efforts. Isr Med Assoc J 2001; 3: 341-346.

7. Althuis MD, Dozier JM, Anderson WF, Devesa SS, Brinton LA. Global trends in breast cancer incidence and mortality 1973-1997. Int J Epidemiol 2005; 34: 405-412.

8. www. nice.org.uk. 